\title{
Cultural Inheritance and Industrial Development of Liuqin Opera
}

\author{
Feng Zhao, Xiao Wang and Xiao-fei HAN ${ }^{\star}$ \\ School of Music Linyi University, Linyi, China \\ ${ }^{*}$ Corresponding author
}

Keywords: Liu Qin Opera, Cultural heritage, Innovation, Industrialization.

\begin{abstract}
Under the background of contemporary cultural ecology, Liuqin Opera, like many local dramas, also faces the crisis of inheritance. Therefore, how to use the method of industrialization to inherit and develop Liuqin Opera, a characteristic local folk music cultural resources, has become an important and urgent research topic. This paper tries to discuss the ways and means to reform and develop the liuqin opera singing and performing form under the background of contemporary culture and ecology, and promote the innovation and industrialization of liuqin drama.
\end{abstract}

\section{柳琴戏文化传承与产业发展研究}

\author{
赵峰, 王霄, 韩小菲 \\ 临沂大学音乐学院,临沂, 中国 \\ “通讯作者
}

关键词: 柳琴戏; 文化传承; 创新; 产业化

摘要: 在当代文化生态背景下, 柳琴戏同许多地方剧种一样, 也面临着传承的危机状态。因 而, 如何运用产业化的方法来传承、发展柳琴戏这一特色化的地方民间音乐文化资源, 就成 为了一个重要的、迫切的研究课题。本文试图以柳琴戏的发展历史及其唱腔特点为切入点, 来探讨在当代文化生态背景下改革、发展柳琴戏唱腔及表演形式, 推动柳琴戏剧目创新及产 业化进程的方法与途径。

\section{1. 柳琴戏的文化意义与价值}

柳琴戏又称 “拉魂腔”、“四平调” 等，一般认为由流行在鲁南地区的民间小唱 “肘鼓 子” 和 “拉魂腔” 相结合而形成, 1952年正式定名为 “柳琴戏”。主要流传的淮海流域属于 “中原官话” 区, 中原官话是中华文明的重要载体, 经华夏祖先数千年沉淀, 语音亦能 “传 神”。而拉魂腔的一些腔调来源于民间巫婆祝词（肘鼓子），可追溯到原始社会，拉魂腔在 民间充当了教化民众, 安定人心的作用。老百姓不识字, 听一段拉魂腔, 就能找到人生的共 鸣、认识古人的世界观, 听一听乡音戏失魂落魄的人能找回最初的自己……声音是人观察世 界的另一个维度。因此可以说拉魂腔是中华民族民间非常宝贵的文化遗产。2006年5月20日, 柳琴戏经国务院批准列入第一批国家级非物质文化遗产名录。

柳琴戏的唱腔, 主要为板腔体, 除慢板、二行板、紧板等板式变化外, 唱段的起、转、 收都有一定的程式化。演员起腔、行腔较自由, 演唱者可以随心所欲的发挥、创造, 自由变 化, 伴奏紧随演唱者唱腔而变化, 交相辉映。男腔粗犵、嘹亮, 女腔婉转、悠扬, 特别是 “叠 句” 和 “祄词”、“衬腔” 的演唱, 生动而有趣, 韵味悠长。拉尾音时, 女腔高八度, 男腔 低五音, 尾音用假嗓, 其它部分男女唱腔都用真嗓, 风格独特。主要伴奏乐器是柳叶琴, 配 以板胡、二胡、横笛和梆子等乐器, 或配以一些管弦乐器。柳琴戏的表演无固定程式, 其身 段、步法多具民间歌舞的特点。演员在舞台上的表演不受拘束，其角色行当，与京剧、梆子 
等叫法不同，如称老生为 “大生” ，彩旦为 “老拐”、小丑为 “勾脚” 等。柳琴戏表演粗犷、 热烈、朴实健康的风格和戏中生动的民间气息以及婉转悠扬, 动人心弦的唱腔和包涵在其中 的诸多古声韵 (姑娘腔等), 具有较高的美学价值。

\section{2. 柳琴戏传承与产业发展研究现状}

同其他地方剧种的现状类似，柳琴戏也面临着传承后继乏人、剧团营生状况恶化、剧团 设备陈旧、人才储备不足等一系列的生存难题。过去柳琴戏主要群众基础来自农村, 现代媒 体兴起尤其是时尚流行音乐文化的冲击, 使得柳琴戏生存市场日渐萎缩。从过去一部戏连演 数十场观众仍热情高涨到后来售票几乎无人问津，表演者与爱好者日渐脱节也是个重要原因

一柳琴戏的群众基础在广大农村而柳琴戏表演团体往往在城市，这也是现代城市化进程带 来的问题。农民的购买力也不足以支撑专业柳琴戏团体商业化的需求, 而听众的喜好会随着 观演关系的变化而变化, 农村的柳琴戏爱好者也逐渐流失。很多创作、表演人员纷纷转行, 加上体制编制的限制, 多数团体人员只退不进, 出现人才断档、青黄不的接现。随着老艺人 相继去世或退休, 在世的也年事已高, 难以登台演出, 也导致部分传统剧目没有得到有效传 承; 也有一些精彩唱腔、唱法和表演艺术濒于失传; 既缺乏叫得响、表演水平高的名角, 也 缺乏编、导、音、美等创作人才, 更缺乏懂艺术、善经营的管理人才。以临沂市柳琴剧团为 例, 每年演出收入日常开支都难以维持, 每逢排演新剧目就捉襟见肘, 难以为继, 设备器材 陈旧难以更新, 基础设施差, 经济条件所限, 严重影响了剧团的生存和发展。

所幸的是，随着国家对传统文化的重视，近年来在各级政府部门关怀下，柳琴戏的剧目 创作保持了一定发展的势头, 近年来推出的《王祥卧鱼》、《䔣海花》、《墨子与鲁班》、

《沂蒙情》等, 都不同程度地引起了一定的社会反响。就笔者掌握的资料来看, 目前关于柳 琴戏文化资源保护与产业化运作的文献已具有一定数量。比如郝媛媛的《非物质文化遗产柳 琴戏的农民本色及其保护对策》（发表于《北方音乐》2011年12期）、杨玉芹的《山东柳琴 戏市场化调查研究》（发表于《戏剧丛刊》2013年第6期）、李美丽的《现代视野中的柳琴戏 市场化探究》（发表于《名作欣赏》2013年第26期）、间辉的《非物质文化遗产柳琴戏的保 护与传承》（发表于《四川民族学院学报》2012年第3期）、徐华云的《山东地方戏传承与保 护对策研究——以山东柳琴戏为例》（发表于《参花》2013年第12期）等一批文献资料。

以上各种文献有效地开拓了本项目研究的视野和思路, 然而以上文献多着重于理论研究 且泛论较多, 缺乏推动柳琴戏剧目创新及产业化进程的具体方法与途径以及理论研究成果。

\section{3. 当代文化生态背景下改革、发展柳琴戏唱腔及表演形式，推动柳琴戏剧目创新及产业化进 程的方法与途径}

\section{1 柳琴戏剧目创作革新}

一个地方剧种要生存、发展, 从根本上说要靠剧目来说话。剧目演出的经济收益和社会 反响, 集中体现了一个剧种在当代的经济和社会价值。目前关于柳琴戏剧目的创作, 大致可 以分为以下几类: 一是对传统剧目的改编, 比如对传统剧目《喝面叶》的精简式改编; 二是 新编历史剧, 如《墨子与鲁班》; 三是现代戏, 如《沂蒙情》。对于剧目的创作, 无论是新 编历史剧还是现代戏, 重要的是用传统的戏曲形式为载体, 来反映出当代人的思维方式、生 活感悟与审美观念。无论是柳琴戏的创作还是其他地方剧种的创作, 首先需要的是反映当代 人思维观念的剧本。要写出这样的剧本, 那么就需要作者既要博通文史, 又要深入生活实践, 这样才能将自己的生活感悟渗透到剧本的字里行间当中去, 从而用历史的或现实的戏曲形式 来反映出当代人的思维习惯和审美观点。然而在近年来山东地方剧种创作、编演的各种人才 不断流失的背景下, 这样的剧本编创人才是不可多得的。这就需要政府在前期加强扶植力度, 为柳琴戏文化减少优秀柳琴戏剧目编创人才流失，产生更多优秀作品。 
另一方面, 需要柳琴戏剧目编创人员不断革新观念, 在剧目创作方面探索更多可能, 使 剧目更贴近时代生活, 更接地气, 把握时代脉搏, 避免空洞乏味, 融入时代精神, 发掘柳琴 戏文化价值。

\section{2 柳琴戏唱腔及表演艺术形式创新}

首先，柳琴戏唱腔及表演艺术形式要继承历史上传承下来的珍贵艺术经验不能盲目 “创 新”。关于地方剧种的唱腔创新, 目前改革与发展的焦点大都在于融入现代的音乐元素和电 声化的配器等方面。这种创新虽然是有益的探索并在一定程度上吸引了部分听众, 然而这种 创新往往具有很大的盲目性, 导致部分作品存在低俗或华众取宠完全失去了柳琴戏艺术本来 的韵味。

其次是要在继承的基础上进行有针对性的创新。我们注意到柳琴戏具有板腔体和曲牌连 缀体戏曲的共同特征, 而且融入了许多山东、苏北地方小调的唱腔, 形式上比较灵活、自由。 因此唱腔音乐方面的创新, 首先就应着眼于将柳琴戏的唱腔发展得更灵活一些。因而, 可以 考虑融入更多的凝聚着鲁、苏、皖等地区民众审美文化心理的民间音乐, 实现它们与柳琴戏 唱腔的 “无缝对接”。

再次, 要从总体上借鉴一些现代歌剧的创作手法。比如柳琴戏中也可以引入歌剧一样的 主题音乐, 用主题音乐来帮助戏曲塑造人物形象, 表现人物的性格特征, 烘托戏曲音乐的氛 围, 这也是柳琴戏音乐创作中值得注意的一点。

最后, 要在表演方面融入更多的、别开生面的元素。比如柳琴戏发轫之初, 行当尚不完 备, 有一人饰演几个角色的情况, 被称为 “来回变”。这种表演形式也可以引入到当前的柳 琴戏表演中来, 然而要加以魔术化的包装。要像川剧变脸那样, 用魔术来展现。这样既符合 柳琴戏自身的艺术特征, 又能够令当代观众耳目一新, 可以说是丰富、发展柳琴戏表演形式 的有效途径。

\section{3 柳琴戏产业化策略}

柳琴戏产业化需要省内文化主管部门应切实协调柳琴戏及其他地方剧种的剧目创作班子 建设。由省级文化主管部门统一组织协调, 从各高校、作家协会、群艺部门等机构抽调合适 的人选, 组成班子, 力争创作出符合当代观众思维及审美习惯的剧本来。后续的唱词、台词 修改, 具体排练等等, 则可主要交给专业的柳琴戏剧团来进行。不仅针对柳琴戏, 其余包括 吕剧、山东琴书等各种地方剧种、曲艺等, 都需要这样的创作班子来提供反映当代观众文化、 思维和审美观念的剧本。

柳琴戏的创新发展及其产业化运作，应着眼于柳琴戏唱腔与同其，有亲缘关系的鲁、苏、 皖民间歌曲进行有机融合的基础上, 总结成功经验, 稳打稳扎地逐步推进。产业化仍要以柳 琴戏的表演为核心, 多创作一些创新性的拳头剧目, 力争在鲁、苏、皖地区乃至更大的地区 内, 获得观众认可, 取得较好的社会经济效益。可将柳琴戏的唱段、元素融入到山水实景类 的综合性文艺演出中去; 可发展柳琴戏为主题的文化旅游项目; 可生产柳琴戏的下游文化产 品; 可建设柳琴戏主题公园等。以多种形式推动柳琴戏的产业化进程, 力争将其打造成为山 东省内一张响当当的文化名片。

\section{Reference}

[1] Feng Guangyu Chinese M. China folk songs of the same clan Federation publishing company, 1998

[2] Editorial board of Chinese folk songs Integration \& Shandong volumes. Integration of Chinese folk songs. Vol. Shandong [M]. China ISBN center, 2000

[3] Editorial board of Chinese folk songs Integration \& Jiangsu volumes. Integration of Chinese folk songs. Vol. Shandong [M]. China ISBN center, 1998 
[4] Liu Qing. Reflections on the "integration" of Shandong folk songs [J]. Symphony (Journal of Xi'an Conservatory of Music), second issue, 2012

[5] Liu Xiaojing of Shandong folk folk songs and the same color area of J. The rheological "Qilu Yiyuan", 2013 fourth 